\title{
Aprendiz circense e contemplador: olhares que dialogam entre a incompletude e o acabamento
}

\author{
Eliane Regina Pereira, ${ }^{I, \star}$ Kátia Maheirie ${ }^{I I}$ \\ ${ }^{I}$ Universidade Federal de Uberlandia, Uberlândia, MG, Brasil \\ II Universidade Federal de Santa Catarina, Florianópolis, SC, Brasil \\ Resumo
}

Este artigo se propõe a apresentar de que forma a arte circense, compreendida como atividade criadora e experiência estética, amplia as possibilidades de "ser" do aprendiz. Tendo uma compreensão teórica da constituição do sujeito como sendo processo sempre inacabado, discutimos como o "acabamento provisório" ofertado pelo contemplador transcende o personagem circense e alcança o sujeito-aprendiz. Por meio de entrevistas e observações das aulas no picadeiro, alcançamos informações a respeito de como o aprendiz define a arte circense e a relação que estabelece com o público, com os colegas de circo e com os professores, dando os indícios da mediação da arte circense na sua constituição. Os resultados da pesquisa apontam para a atividade circense como capaz de se fazer mediação na constituição do sujeito a partir do olhar do contemplador, que ofertando significados ao aprendiz, amplia suas possibilidades de ser.

Palavras-chave: constituição do sujeito; atividade criadora; experiência estética; escola de circo; alteridade.

\section{Apprentice circus and beholder: looks that dialogue between the incompleteness and the finishing}

\begin{abstract}
This article aims to show how the circus arts, understood as creative activity and aesthetic experience, expands the possibilities of "being" of the apprentice. Having a theoretical understanding of the constitution of the subject to be never-ending process, we discussed how the "provisional finishing" offered by the beholder transcends circus character and reaches the subject-apprentice. Through interviews and observations of lessons in the circus ring, we reach information about how the student sets the circus arts and the relationship established with the public, with the circus colleagues and teachers, giving the evidence the mediation of circus arts in its constitution. The survey results point to the circus activity as capable of doing mediation in the constitution of the subject through the eyes of the beholder, which meant offering the apprentice, expanding your chances of being.
\end{abstract}

Keywords: constitution of the subject; creator activity; aesthetic experience; circus school; otherness.

\section{Introdução}

O presente trabalho consiste em um recorte da pesquisa realizada em uma escola de circo cujas reflexões versam sobre a atividade circense enquanto atividade criadora e experiência estética. Para a psicologia histórico-cultural é "através da atividade humana que o ser humano transforma o contexto social no qual se insere e nesse processo constitui a si mesmo como sujeito, ou seja, constituiu o seu psiquismo" (ZANELLA, 2005, p. 101). A atividade humana pode se caracterizar na simples repetição de algo já criado, como pode ir além, criando algo novo, imaginando novas situações, definindo-se como atividade criadora (VIGOTSKI, 1999).

Por atividade criadora compreendemos, a partir de Vigotski (2009) e o círculo de Bakhtin (1976[1926], 2003), que o sujeito parte da realidade e a transforma, transformando-se neste movimento, a partir do modo como, neste processo, (re) significa o seu contexto e a si mesmo. A atividade é criadora, então, quando o sujeito partindo dos elementos percebidos na realidade e (re) configurados na imaginação, produz algo novo. A atividade criativa ou criadora transcende o cotidiano, permitindo que o sujeito se distancie em relação a ele e, emocionando-se diferentemente, objetive uma subjetividade.

\footnotetext{
^Endereço para correspondência: Universidade Federal de Uberlândia, Instituto de Psicologia. Av. Pará, 1720 - Umuarama. CEP: 38400902 - Uberlândia, MG - Brasil.E-mail: eliane@ipsi.ufu.br,maheirie@gmail.com
}

Deste modo, as objetivações artísticas, neste caso a atividade circense, passam a ser compreendidas como espaço de produção de novos sentidos, como possibilidade de experimentar diferentemente o cotidiano. Esta atividade criadora se faz experiencia estética, "enquanto dimensão sensível, enquanto modo específico de relação com a realidade, pautado por uma sensibilidade que permita reconhecer a polissemia da vida e transcender o caráter prático utilitário da cultura capitalística [...]" (ZANELLA, 2006, p. 36). Ao tornar-se artista circense o sujeito não demonstra seus "dons" ou "qualidades inatas", mas apresenta qualidades provenientes de sua história, de seu desejo de ser, mas acima de tudo, neste espaço (re) descobre sua história, (re) descobre seu desejo de ser.

A discussão aqui proposta centra-se na relação de alteridade, e no olhar do contemplador, que conferindo acabamento ao personagem, media a constituição dos sujeitos-aprendizes. Por acabamento Bakhtin (2003) esclarece que é o sentido de que algo tem inicio, meio e fim, e por ter fim, ter limite, é que se abre para fora de si mesmo, ou seja, produz exterioridade e permite ao contemplador produzir sua leitura, sua interpretação, seu sentido. No caso do circo, o personagem tem acabamento, o que permite ao contemplador produzir sentidos sobre ele, sentidos estes que transcendem o personagem e alcançam o sujeito/aprendiz. 
O picadeiro se apresentando como contexto e método

A pesquisa de doutorado foi realizada com doze aprendizes circenses e quatro educadores de uma escola de circo, estabelecida no município de Penha, Santa Catarina.

Para a coleta das informações os pesquisadores inicialmente vídeo gravaram aulas no picadeiro da escola e algumas apresentações por eles realizadas. $\mathrm{Na}$ sequencia, foram entrevistados os quatro educadores do Circo Escola, a fim de compreender como eles percebem seus aprendizes; como e o que avaliam no processo de ensinar e aprender. Logo, terminadas as entrevistas com os educadores, os aprendizes foram convidados a participar de uma entrevista coletiva sendo organizados cinco grupos de dez aprendizes, cuja conversa versou sobre como iniciaram as atividades no Circo Escola; quais as motivações para permanência; quais as atividades circenses que mais gostavam de realizar e como realizaram a escolha pelas mesmas; que outras experiências tiverem com "arte" além do Circo Escola e finalmente, como definem o circo. Após as entrevistas coletivas, 12 sujeitos foram selecionados para as entrevistas individuais, tendo como critério um "envolvimento afetivo com a atividade" que foi para nós destacado com a resposta a pergunta: "como define o circo?". Nosso recorte aqui destaca as falas de sete aprendizes, Samantha, ${ }^{1}$ Bianco, Elena, Jaque, Emílio, Berenice e Penélope, acerca de como definem a relação que estabelecem com a plateia, aqui denominados contempladores, dando os indícios da mediação da arte circense na sua constituição.

O método foi ancorado nos aportes teóricometodológicos Vigotski e Bakhtin vindo a contribuir com uma perspectiva dialógica de análise. Quando falamos em dialogia, nos referimos a Bakhtin (2003) que propõe esta como fundante da relação entre os sujeitos. Para o autor é necessário compreender que sempre que dois sujeitos se encontram, desta relação nasce um discurso, que se apresenta como historicidade, relação sempre provisória e inacabada. Discurso, aqui, é entendido como aquele produzido a partir de toda e qualquer relação social e que, necessariamente, se abre para uma coautoria, uma resposta do outro, por isso, se faz possibilidade de produção de novos sentidos.

\section{Sujeito-aprendiz: relações de incompletude e acabamento}

Sujeito incompleto ou sujeito acabado. De que sujeito falamos? Se partimos de uma perspectiva históricocultural, compreendemos que o sujeito se constitui, que ele não tem sua subjetividade determinada a priori, nem acabada no presente, mas que seu "Eu" sempre inacabado, inconcluso, resulta do modo como interage socialmente e se apropria do contexto.

Compreendemos, a partir de Vigotski, que o sujeito se constitui ao se apropriar dos signos a ele apresentados nas relações sociais. Essa apropriação se dá sempre de forma singular, ou seja, cada sujeito se apropria das coisas e das relações do mundo de forma única, a partir

\footnotetext{
${ }^{1}$ Todos os nomes apresentados neste texto são fictícios.
}

do momento e do lugar que ocupa no mundo, sendo singular em um específico conjunto de circunstancias. Somos únicos, porque cada relação que vivenciamos é única e irrepetível, mas, ao mesmo tempo, somos semelhantes porque vivemos num mesmo contexto histórico e por esse motivo, não fugimos aos limites da época e da organização social. Para que este sujeito se torne singular, este processo se faz na vivência dialética/ dialógica da objetivação/subjetivação.

O sujeito se apropria dos significados que são coletivos, singularizando-os para que se possa objetiválos em ações, pensamento, emoções. Portanto, é a partir destes sentidos que o sujeito tem possibilidade de compreender e agir no mundo (ZANELLA, 2005). Deste modo, é através do outro - sujeito, contexto, linguagem - que constituímos o Eu. Bakhtin (2003) escreve que a consciência tem uma materialidade sígnica, porque esta passa a existir quando "entra em relação com os outros" e a partir daí internaliza os signos dessa relação. Esta relação com outro, mediador da constituição do sujeito, é o que chamamos alteridade.

Quando fala de alteridade, Zanella (2005, p. 103) escreve que "só há sujeito porque constituído em contextos sociais, os quais, por sua vez, resultam da ação concreta de seres humanos que coletivamente organizam seu próprio viver". Nossa existência é dirigida ao outro, que ativamente produz sentidos sobre nós, e assim se faz mediação em nossa constituição.

Compreendemos o sujeito como se constituindo, como processo, portanto totalização e inacabamento. $\mathrm{O}$ inacabamento do sujeito é o que faz dele um ser responsável por sua constituição, uma vez que reagindo diante da vida, ele se (re) faz, se (re) cria.

Mas esse sujeito inacabado e capaz de criar-se, só o faz, porque se relaciona a todo o momento com um "outro", outro que the confere acabamento, the define como alguém, e então, quando se percebe como totalidade - um acabamento provisório - é que o sujeito se abre para a possibilidade de (re) criação. É a totalidade que potencializa a produção de sentidos e funda uma dinâmica de renovação da existência. Geraldi (2003) explica que o acabamento é o sentido de que algo tem começo e fim, e porque tem um fim, tem um limite que se abre a ela possibilidades de sentidos. Diz o autor "nosso acabamento atende a uma necessidade estética de totalidade, e esta somente nos é dada pelo outro, como criação e não como solução" (GERALDI, 2003, p. 47).

Como são inúmeros os outros com os quais o sujeito estabelece relações de alteridade, este sujeito torna-se espaço de síntese de outros sujeitos. Cada ser é então, a síntese de múltiplas determinações, síntese no sentido de apropriação do discurso do outro, daquilo que faz seu a partir do outro. Síntese que se apresenta como totalidade provisória no presente, mas se define pela relação entre o passado e o futuro. A memória ${ }^{2}$ de passado, como nos

${ }^{2} \mathrm{O}$ autor acrescenta ao passado e ao futuro, a palavra memória, para afirmar que estes não são vividos no presente nas suas condições reais, mas sim, a partir da significação que o sujeito confere a eles. O sujeito (re) compõe o passado na produção de sentido e este é revivido no presente, o mesmo ocorre com o futuro, cuja imaginação o presentifica. 
explica Bakhtin é a objetivação da história do sujeito, de como se constituiu, ela é quem oferece as condições de existência do sujeito. A memória de futuro é a dimensão subjetiva que dirige o sujeito ao por vir, aquilo que está por ser alcançado e que consequentemente oferece possibilidades de ação.

Bakhtin (2003, p. 128) escreve que o sujeito se constitui como sujeito em ação, sujeito de volição, sujeito de desejo. "Sua vida [...] é a cada momento um agir: eu ajo através do ato, da palavra, do pensamento, do sentimento; eu vivo, eu me torno um ato".

É a memória de passado e a memória de futuro que determinam os critérios de valor, com os quais o sujeito seleciona suas possibilidades, o que faz deste processo de constituição um processo de criação.

\section{$O$ contemplador: alteridade que confere acabamento e transcende o personagem}

Em uma gincana da escola que eu estudo, tínhamos que fazer um "cover" de uma trupe de circo já conhecida. Então, criamos um número de acrobacia, "cover da África Misteriosa". O [professor] ficou sabendo da apresentação na escola e sugeriu que apresentássemos para ele. Ele mexeu em alguns detalhes, nos opinamos em outros $e$ juntos, criamos o número de acrobacia que apresentamos ainda hoje. Definimos com ele o tipo de roupa que iríamos usar, porque na gincana usamos roupas parecidas para o "cover", mas ele sugeriu algo mais clássico, dai pensamos e enfim, criamos juntos, aquela roupa vermelha que você já deve ter visto. Claro, apresentamos muita coisa que ele cria, mas ele permite nossa participação, nossa opinião também. Isso é muito bom (Leopoldo).

Leopoldo é um dos aprendizes circenses, sujeitos da pesquisa, e sua fala esclarece o quanto o aprender circense lhe permite ser autor da personagem que apresenta no picadeiro. É acreditando na autoria de cada um dos sujeitos aprendizes, e com base em Bakhtin (1976[1926], 2003) que destaca a existência de uma tríade fundamental à arte: o autor, o ouvinte, e o herói; que definimos que no caso do circo o aprendiz é autor e personagem, o ouvinte ou contemplador é a plateia, real ou imaginária com o qual o autor dialoga na apresentação ou ainda na criação, e o herói é a apresentação, com seu inicio, meio e fim.

O autor/aprendiz, pessoa, é inacabado, mas o personagem, a obra, tem acabamento. Toda a criação é mediada pelo contemplador, alguém real ou não, com quem o autor/aprendiz imagina e dialoga no momento da criação artística, e que durante a apresentação da obra se materializa nos pais, amigos, professores e na plateia em geral. Há, portanto, uma relação afetivo-volitiva entre o autor/aprendiz/personagem e o público, que se complementam, tornando-se relação estética.

O papel do contemplador foi destaque em muitas falas das entrevistas, entre elas, as de Samantha.

[...] eu nunca tive lá, eu acho que é uma coisa bem legal tu ser aplaudido pelo público. O público sai dali satisfeito, então eu acho que se um dia eu for fazer um show, eu acho que vou fazer bem feito por que é uma coisa que dá muito gosto pra gente que vai fazer.
Samantha apresenta em sua fala, a mediação do contemplador, aquele que ela idealiza, com quem ela dialoga no processo de criação e que ainda não foi materializado, pois ela ainda não experimentou o palco para apresentação.

$\mathrm{Na}$ arte circense, o autor/aprendiz sendo personagem, tem a possibilidade de dialogar com outro contemplador, o sujeito real, que se expressa pelo aplauso, pelo grito, pelo registro fotográfico, que servem para o autor/aprendiz como entoação, que possibilitam a ele uma produção de sentidos outra que o afeta, não apenas como personagem, mas fundamentalmente como autor/aprendiz.

$\mathrm{O}$ poeta trabalha constantemente em conjunção com a simpatia, com a concordância ou discordância de seus ouvintes. [...] Ouvinte e herói são participantes constantes do evento criativo, o qual não deixa de ser nem por um instante um evento de comunicação viva envolvendo todos os três (BAKHTIN, 1976[1926], p. 10).

O contemplador é coautor do espetáculo, ofertando ao autor/aprendiz uma produção de sentidos que transcende o personagem e confere acabamento ao sujeito. O contemplador, durante e depois do espetáculo é convidado a dialogar com os personagens. Cada gesto, cada movimento, a música, as luzes, provocam estranhamento no contemplador, que deixa de identificar os sujeitos do dia a dia, mas se impressiona com os personagens, sua destreza, força e habilidades.

[...] vejo que a plateia se impressiona com as coisas que a gente faz, ... demonstra um pouco assim, que você ta fazendo uma coisa que realmente ta impressionando eles, por mais que ainda não esteja correto, mas você já vê que isso já começa a te animar mais, pra você continuar fazendo alguma coisa realmente impressionante (Bianco).

Bianco, fala de si como sujeito, muito mais do que do que do personagem que está sendo. O olhar e a euforia da plateia ratificam o autor/aprendiz, de tal modo, que o permite falar de si, como alguém que realiza coisas impressionantes, como se a cada dia se descobrisse capaz de novos feitos.

É incrivel, é incrivel, o pessoal, a gente olha o pessoal tudo rindo, sorrindo, alegre, a gente faz a pessoa sorrir entendeu? (Elena).

A fala de Elena nos permite pensar que no momento em que olha para os contempladores, e se percebe vista por eles, ela se (re) conhece, se (re) descobre, e naquele momento se faz outra de si mesma.

[Na coreografia das] [...] guerreiras ${ }^{3}$, a gente tem medo de cair, qualquer coisa, ai depois que eles batem palmas, a gente fica ali em cima, a autoestima fica lá em cima (Jaque).

A fala de Jaque não é diferente das falas de Elena e Bianco. Jaque fala de si, dos seus medos, das suas dificuldades e da possibilidade de superação e (re) descoberta de si, vivenciada na relação com o contemplador. A relação autor/aprendiz-contemplador se apresenta pautada por uma

\footnotetext{
3 "As guerreiras" é um número circense, conhecido como pirâmide humana. Nesta escola e nos espetáculos por ela apresentados, a pirâmide é composta por quatro meninas na base, e dois outros degraus, composto por três e duas meninas. A performance exige força, ritmo, harmonia ancoradas na ideia de leveza.
} 
relação estética, possibilitando a cada artista a produção de sentidos outros que os torne sensíveis a sua própria história, e assim ampliem as suas possibilidades. O contemplador é, portanto constitutivo do autor/aprendiz, confere a ele um acabamento que transcende os limites do personagem e alcança o sujeito. Nesse momento, o contemplador se faz mediação na constituição do sujeito ampliando suas possibilidades de ser.

Então, quem são os contempladores? Como esses "aprendizes circenses", são por eles afetados?

Durante as entrevistas, fica evidenciado a presença de diferentes contempladores, com os quais se estabelece diferentes momentos de comunicação estética.

O que caracteriza a comunicação estética é o fato de que ela é totalmente absorvida na criação de uma obra de arte, e nas suas contínuas re-criações por meio da co-criação dos contempladores, e não requer nenhum outro tipo de objetivação (BAKHTIN, 1976[1926], p. 4).

No circo, quando o contemplador é a família, a entoação dada pelo autor/aprendiz, determina o lugar do outro, como possuidor de uma voz que revela um conhecimento sobre o autor/aprendiz, mais do que sobre o personagem. O acabamento ofertado ao personagem alcança o autor/aprendiz e lhe confere acabamento, como nos revela Jaque: [...] das guerreiras, ela [a mãe] elogia bastante, ela disse que não imaginava que eu teria aquela força toda. Ela disse pros guris da sala ficarem com mais medo de mim, meu Deus.

Jaque fala da mãe contempladora, que se faz alteridade e lhe possibilita a construção de novos sentidos. Jaque entende então, que a força da personagem - guerreira - é sua força, e pode se apresentar em outros contextos e para outras pessoas, como os meninos da escola. A força da guerreira pode se constituir força da menina, proporcionando a catarse do autor/aprendiz. Sawaia (2006, p. 90) explica que a catarse tem como efeito a reorganização das funções psicológicas superiores, que mediada pela imaginação e pelo afeto, tem impacto cognitivo e afetivo no sujeito, "permitindo ao homem superar os seus limites particulares".

O olhar da mãe contempladora transforma as emoções de Jaque por meio da experiência estética e direciona as emoções, como estímulo para novas ações. É a partir da contemplação da mãe, que a arte alcança Jaque e ela compreende que é forte, se constitui como "forte".

As relações artista-contemplador revelam que o acabamento ofertado ao personagem, tem em si, presumidos que vão constituindo a vida desses sujeitos.

[...] minha mãe gosta bastante e meu pai melhor ainda, ele admira bastante, entendeu? Por que não é muitas vezes que ele vê eu, fazendo show entendeu? Porque ele mora longe entendeu? Não tem como ele vir pra cá mais. [...] a ele adora né. Até um dia ele veio aqui [...] ele viu eu fazendo, meu Deus ele quase saiu chorando, de tanta emoção que ele viu eu fazer (Emílio).

[...] minha mãe tirava foto levava pro emprego, essa é minha filha toda orgulhosa toda boba, meu pai também

\section{dava bastante parabéns pra mim [...] (Berenice).}

Emílio e Berenice falam de orgulho, de emoção, de admiração, sentimentos que transcendem a personagem e alcançam o autor/aprendiz. Mas é Elena quem declara os presumidos que ela compreende quando a mãe é ouvinte/ contempladora.

[...] quando a gente inangurou o Aladim aqui no circo, quando ela (a mãe) veio, eu tava dançando o rola-rola né, do menininho lá, quando olhei assim a expressão do rosto da minha mãe sabe, ali ta, da vontade de parar e ir ali abraçar ela, assim não tem? Porque é lindo, é um orgulho, bem, não sei, diferente de explicar, assim é bem gostoso. [começa a lacrimejar] é como se ela dissesse, continua, continua que tu chega lá (Elena).

Para ela, o orgulho que a mãe sente, serve como acabamento artístico, mas principalmente como memória de futuro do sujeito que aponta aonde quer chegar. No fazer, Elena encontra o fazer-se outro, e o "orgulho" da mãe contempladora confere a Elena uma totalidade provisória que imprime um sentido estético, que lhe impulsiona a um possível outro no porvir.

Outros contempladores importantes são os amigos próximos, isso porque, eles contemplam a beleza, a suavidade dos movimentos, a precisão da ação, mas abstraem dela o esforço, a força, o treinamento, e isto, oferta ao autor/aprendiz, um acabamento que o faz projetar cenários outros para se definir.

[Os amigos que não fazem aula de circo] [...] acho que eles ficam pensando que eu sou uma pessoa persistente naquilo que eu quero fazer (Samantha).

O que cada um dos entrevistados apresenta em suas falas e assim, o que acreditam, é que os contempladores demonstram valorização pelo que eles fazem. E a sensação que se apresenta pela valorização - a felicidade - se encontra em fazer-se outro de si mesmo, um outro que Samantha define como "sou persistente".

eles não sabem como é, eles ficam, meu Deus, como se fosse um mundo mágico. Meu Deus você esta no circo, como que é, é legal? ... que legal você me leva um dia pra assistir? ... então é por isso que tens um corpo todo durinho? eles perguntam. Eles começam a tocar e dizem, meu deus é tudo duro, que, que é isso, é porque eu faço aula de circo escola, . eu sou gordinha né (Penélope).

Durante a entrevista, Penélope revela que o fato de "ser gordinha" muito a incomoda. Diz que precisa superar os comentários do professor da escola de circo, os comentários de sua mãe, e de outras pessoas que a provocam por não perder peso apesar de suar, nas aulas de circo. Quando fala sobre o fato de estar acima do peso, Penélope se aliena na relação com o outro, se perde no olhar que o outro dispara ao seu corpo e que experimenta como se ficasse em poder dos outros, como se não pudesse ser dona de si e precisasse se explicar, se justificar. Mas outros contempladores têm ofertado a Penélope uma possibilidade de superação e, assim, mediado sua relação consigo mesma, onde Penélope passa a destacar aspectos do seu corpo que ela admira que valoriza. Desse modo, Penélope, supera a condição 
de alienação estabelecendo outra relação eu-outro, uma relação de estar com o outro Penélope se lança a um determinado futuro onde transcende o "ser gordinha" e se totaliza em imaginação com um corpo que apesar de não alcançar os padrões de beleza da sociedade, pode ser interessante e por isso aceito.

\section{Ofertando acabamento}

Pode-se entender que a atividade circense se faz mediação na constituição do sujeito ampliando suas possibilidades de ser, mostrando que "cada minuto está cheio de possibilidades não realizadas, o comportamento que se realizou é uma parte insignificante dos comportamentos possíveis" (VIGOTSKI, 2004, p. 69).

Alicerçada na compreensão de constituição, onde o sujeito é definido como inacabado, portanto totalização aberta, as entrevistas nos permitiram refletir sobre a relação de acabamento provisório, ou seja, totalidade imaginária, que sendo ofertada por um contemplador, é apropriada pelo sujeito como definindo o seu EU. Para Sartre (2007) é com o corpo que o sujeito experimenta, sente e significa as relações. Ao mesmo tempo, nas relações que o sujeito estabelece, o corpo é visto pelo outro, e ao ser visto é significado pelo outro e (re) significado pelo sujeito, que então (re) define-se.

Fica evidenciado que sempre que o contemplador oferta determinadas características aos personagens, apontando significados ao corpo do artista, estas alcançam o sujeito/aprendiz, que se modifica quando as percebe como sendo suas. O circo, portanto, antes de ser compreendido intelectualmente pelo sujeito, é sentido, é vivido, se faz experiencia, marca os sujeitos aprendizes e os transforma como sujeitos, modificando a maneira como compreendem e agem no mundo.

Vázquez (1999, p. 94) explica que a relação estética "implica que a atenção do espectador se desloque para a sua forma sensível". O olhar do outro confere valor estético ao personagem, o que facilita a entrega do autor/ aprendiz para a criação quando este percebe que sua obra é aceita pelos outros. São esses olhares estéticos dirigidos aos personagens que oferecem ao autor/aprendiz uma oportunidade de vivencia estética, uma possibilidade de significação outra, diferente da experiência anterior.

As conclusões permitem inferir que quando o contemplador aplaude, grita e elogia, o aprendiz significa essas ações e presume ser um artista e, ao se perceber vistos por eles, eles se (re) conhecem e se (re) descobrem, fazendo-se outro de si mesmo, ampliando suas possibilidades de ser. O que é possível compreender é que o contemplador confere acabamento ao personagem, acabamento que transcende o personagem e alcança o sujeito conferindo a este um acabamento provisório. É este acabamento provisório, mas situado, contextualizado, que abre para o sujeito novas significações, que permite o sujeito (re) significar-se.

\section{Referências}

BAKHTIN M. Discurso na vida e discurso na arte: sobre poética sociológica (1926). Tradução de Carlos Alberto Faraco e Cristóvão Tezza. In: VOLOCHINOV, V. N. Freudismo. New York: Academic Press, 1976. p. 01-16.

BAKHTIN M. Estética da criação verbal. Tradução de Paulo Bezerra. São Paulo: Martins Fontes, 2003.

GERALDI J. W. A diferença identifica. A desigualdade deforma. Percursos bakhtinianos de construção ética e estética. In: FREITAS, M. T.; JOBIM e SOUZA, S.; KRAMER, S. (Org.). Ciências humanas e pesquisa: leitura de Mikhail Bakhtin. São Paulo: Cortez, 2003. p. 39-56.

SARTRE, J.-P. $O$ ser $e$ o nada: ensaio de ontologia fenomenológica. Tradução de Paulo Perdigão. Petrópolis, RJ: Vozes, 2007.

SAWAIA, B. B. Introduzindo a afetividade na reflexão sobre estética, imaginação e constituição do sujeito. In: DA ROS, S. Z.; MAHEIRIE, K.; ZANELLA, A. V. Relações estéticas, atividade criadora e imaginação: sujeitos e (em) experiência. Florianópolis: NUP/CED/UFSC, 2006. p. 85-94.

VÁZQUEZ, A. S. Convite à estética. Tradução de Gilson Baptista Soares. Rio de Janeiro: Civilização Brasileira, 1999.

VIGOTSKI, L. S. Psicologia da Arte. Tradução de Paulo Bezerra. São Paulo: Martins Fontes, 1999.

VIGOTSKI, L. S. Teoria e método em Psicologia. São Paulo: Martins Fontes, 2004.

VIGOTSKI, L. S. Imaginação e criação na infância. Tradução de Zoia Prestes. São Paulo: Ática, 2009.

ZANELLA, A. V. Sujeito e alteridade: reflexões a partir da Psicologia Histórico-Cultural. Psicologia e Sociedade, [S.1.], v. 17, n. 2, p. 99-104, maio/ago. 2005. Disponível em: <http:// www.scielo.br/pdf/psoc/v17n2/27049.pdf/>. Acesso em: 20 jul. 2013.

ZANELLA, A. V. "Pode ser flor se flor parece a quem o diga": reflexões sobre Educação Estética e o processo de constituição do sujeito. In: DA ROS, S. Z.; MAHEIRIE, K.; ZANELLA, A. V. Relações estéticas, atividade criadora e imaginação: sujeitos e (em) experiência. Florianópolis: NUP/CED/UFSC, 2006. p. 33-47.

Recebido em: 9 de agosto de 2013 Aceito em: 25 de setembro de 2015 